\title{
The knowledge and opinions of urology doctors in Turkey of hyperbaric oxygen therapy in radiation-induced hemorrhagic cystitis: a survey study
}

\author{
Üroloji doktorlarının radyasyona bağlı hemorajik sistitte hiperbarik oksijen tedavisi \\ uygulamasına dair bilgi düzeyleri ve görüșleri: anket çalıșması
}

\section{Kubra Ozgok Kangal ${ }^{1}$, Kubra Canarslan Demir ${ }^{1}$}

1 University of Health Sciences- Gülhane Training and Research Hospital, Department of Undersea and Hyperbaric Medicine, Ankara, Turkey

Submitted: 2020-11-06

Accepted: 2021-03-15

\section{Correspondence \\ Kübra Özgök Kangal \\ Emrah, Gata No:87, 06010 Etlik, \\ Keçiören / Turkey \\ e-mail: kubra_ozgk@hotmail.com \\ T: +90543781 1424 \\ ORCID \\ K.O.K. 0000-0002-2449-4821 \\ K.C.D. 0000-0001-6911-2375}

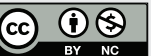

This work is licensed under a Creative Commons Attribution-NonCommercial 4.0 International License.
Özet

Amaç: Radyoterapiye bağlı gelişen hemorajik sistit (RHS), hiperbarik oksijen tedavisi (HBOT) için kabul edilmiş bir endikasyondur. Çalışmamızda üroloji doktorlarının RHS'de HBOT hakkındaki bilgi düzeylerini ölçmeyi ve HBOT’e dair görüşlerini analiz etmeyi amaçladık.

Gereç ve Yöntemler: Üroloji alanında uzman olan veya uzmanlık eğitimi alan doktorlara yüz yüze veya online yöntemle anket uygulanmıştır.

Bulgular: Çalışmamıza katılan 77 hekimin üroloji alanındaki ortalama deneyimleri $11 \pm 10,5$ yıldı. Hekimlerimizin \%84,4'ü kendilerine bir yılda ortalama 0-10 RHS hastasının başvurduğunu belirtti. Ancak hekimlerin çoğunluğu (\%61) RHS hastalarını HBOT’ye hiçbir zaman yönlendirmediğini bildirdi. Benzer şekilde HBOT hakkında uzmanlık alanı için yeterli bilgisinin olmadığını ifade eden hekimler çoğunlukta $(\% 48,1)$ idi. Diğer yandan hekimlerin \%54,5'i HBOT'nin RHS hastalarında etkili bir tedavi olması, \%66,2'si maliyet etkin bir tedavi seçeneği olması ve $\% 49,9$ 'u iyileşme süresini kısaltması hakkında görüşlerini emin olmadıkları yönünde belirtmişti. HBOT hakkında hiçbir bilgisi olmayan hekimlerin, diğer hekimlere göre RHS hastalarını HBOT'ye yönlendirme oranlarının istatistiksel olarak anlamlı șekilde daha az olduğu ve HBOT'nin RHS hastalarında etkili bir tedavi olduğuna dair daha olumsuz görüşlere sahip olduğu görüldü (sırasıyla $\mathrm{p}<0,001$, $\mathrm{p}=0,002$ ). Son olarak, RHS başvurusu alan hekimlerin, RHS başvurusu almayan hekimlere göre HBOT hakkında RHS hastalarında tedavi etkinli-
Abstract

Objective: Radiation-induced hemorrhagic cystitis (RHC) is an accepted hyperbaric oxygen therapy (HBOT) indication. We aimed to analyze the knowledge and the opinions of urology physicians on HBOT in RHS patients with a survey.

Materials and Methods: The questionnaires were conducted face to face or online on urology physicians.

Results: Seventy-seven urology physicians participated in our study. Physicians have been working for $11 \pm 10.5$ years in the field of Urology. The $84.4 \%$ of our physicians had an average of $0-10$ RHC patient administration in a year. However, the majority of the participants stated that they have never referred RHC patients to HBOT. Similarly, $48.1 \%$ of the physicians stated that they have insufficient knowledge of HBOT for their specialty. On the other hand, the majority were not sure about the HBOT as an effective treatment option in RHC patients (54.5\%), about the cost-effectiveness of HBOT for RHC (66.2\%), and the ability of HBOT on shortening the recovery period of RHC patients (49.9\%). We observed that physicians who did not have any knowledge on HBOT had statistically significantly lower RHC patient referral rates to HBOT and had more negative opinions on the effectiveness of HBOT in RHC patients (respectively $\mathrm{p}<0.001, \mathrm{p}=0.002$ ). Likewise, physicians who had RHC patient admissions had statistically significantly more positive opinions about HBOT in terms of treatment efficiency, shortening the re- 
ği, iyileşme süresini kısaltması ve güvenli bir tedavi olması ile ilgili görüşlerinin istatistiksel anlamlı bir biçimde daha olumlu olduğu görüldü (sırasıyla $\mathrm{p}<0,001, \mathrm{p}<0,001, \mathrm{p}<0,001$ ).

Sonuç: Bu çalışmada üroloji hekimlerimizin çoğunluğunun RHS hastalarında HBOT uygulaması hakkında bilgi düzeylerinin yeterli olmadığını gördük. Bu nedenle RHS' de HBOT uygulaması hakkında kararsızlı̆ın hakim olduğunu ve pratik uygulamada hekimlerimizin çoğunluğunun RHS hastalarını HBOT için yönlendirmediklerini fark ettik.

Anahtar Kelimeler: hiperbarik oksijen tedavisi, sistit, radyasyon hasarı, mesane, ürologlar covery period, and being a safe treatment option in RHC patients compared to the physicians who did not have any RHC patient admissions (respectively $\mathrm{p}<0.001, \mathrm{p}<0,001, \mathrm{p}<0.001$ ).

Conclusion: We found that the urology physicians' knowledge of HBOT application in RHC patients was insufficient. Thus, we realized that they were doubtful about HBOT as an effective RHC treatment option. Likewise, we found out that most of the urology physicians do not refer RHC patients for HBOT.

Keywords: hyperbaric oxygen therapy, cystitis, radiation injuries, bladder, urologists

\section{GiRiş}

Pelvik kanserlerin tedavisinde yaygın bir şekilde kullanılan radyoterapi, akut veya kronik dönemde birçok komplikasyona sebep olabilmektedir. Günümüzde teknolojik gelişmeler sayesinde sağlıklı dokular radyasyona daha az maruz birakılmakta; böylece daha az komplikasyon oluşmaktadır. Yine de tam olarak yan etkilerin önüne geçilememiştir. Ayrıca, eski yöntemlerle radyoterapisini tamamlamış birçok hasta, hala ciddi üriner komplikasyonlarla başvurmaktadır (1). Prostat kanseri nedeniyle uygulanan radyoterapinin ardindan kronik idrar yolu komplikasyonlarının görülme sıklığının \%5,7-11,5 arasında olduğu bildirilmiştir $(2,3)$.

Radyasyona maruz kalan dokular; hipovasküler ve hipoksik bir dokuya dönüşerek ilerleyici bir endarterit ile beraberlik gösterebilir. Bu dokularda hücresel ve hücre dışı yenilenme yeteneği azalmaktadır (4). Radyoterapinin sebep olduğu bu doku hasarı sonucunda fistül oluşumu, kontraktürler ve striktürler gelişebilir (5). Radyoterapiye bağlı gelişen hemorajik sistit (RHS) ise tedaviden sonraki 20 yıla kadar görülebilen ve ölümcül seyredebilen bir komplikasyondur (6). RHS görülme sıklı̆̆ \%3-6,5 arasında bildirilmektedir (3,7). Son evre RHS hastalarında uygulanan üriner diversiyon ve sistektomide mortalite oranı ise \%44'e kadar çıkmaktadır. İlk olarak konservatif tedavi ile takip edilen hastalara hidrasyon/diürez, mesane irrigasyonu ve gerektiğinde transfüzyon tedavisi yapılmaktadır. Şiddetli refrakter RHS hastalarında ise sistektomiye kadar gidilebilmektedir. Hiperbarik oksijen tedavisi (HBOT) de RHS için bir tedavi seçeneği olarak kullanılmaktadır (8).
HBOT, doku oksijenasyonunu arttırır, neoanjiyogenezi uyarır ve fibrozisi azaltır (9). HBOT uygulanan RHS hastalarında tam başarı oranı çalışmaların çogunda \%75'den fazla olarak bildirilmektedir (10). Ancak HBOT merkezlerinin az sayıda olması, her ilde bulunmaması nedeniyle ülkemizde ve dünyada iyi bilinen bir tedavi yöntemi değildir (11). Özellikle çalıştıkları hastanelerde HBOT merkezi bulunmayan birçok doktorumuz HBOT uygulamaları ile sadece çalışmalarda veya bilimsel toplantılardaki sunumlarda karşılaşmaktadır. Tüm dünyada oldukça sık görülen RHS vakaları için, yüksek tedavi başarısına sahip olduğu bildirilen HBOT için hasta başvuruları oldukça az sayıdadır (12).

$\mathrm{Bu}$ çalışmada üroloji doktorlarının RHS'de HBOT kullanımı hakkındaki bilgi düzeylerini ve HBOT’e dair görüşlerini hazırladığımız anket ile analiz etmeyi amaçladık. İkincil amacımız ise RHS'de başarılı bir tedavi seçeneği olarak HBOT hakkında farkındalığı arttırmaktır.

\section{GEREÇ VE YÖNTEMLER}

Çalışmamızda tarafımızca hazırlanan anketler Mart 2020 - Nisan 2020 tarihleri arasında Uluslararası Laparoskopik Robotik Cerrahi Derneği (ILRSA) ve Türk Üroloji Derneği İç Anadolu Şubesine üye olan üroloji doktorlarına yüz yüze veya online yöntemle uygulanmıştır. Çalışmaya dahil edilme kriterleri arasında; (i) üroloji alanında uzmanlığını almış veya üroloji uzmanlık eğitimini aktif olarak sürdürmek, (ii) aktif 
olarak Üroloji alanında çalışmaya devam etmek (iii) uzmanlık öğrencisi olan hekimlerin en az 1 yıldır üroloji alanında eğitimlerini almakta olması yer almaktadır. Çalışmadan dışlama kriterleri arasında (i) anketi doldurmayı kabul etmemek, (ii) aktif olarak üroloji dışında bir uzmanlık dalında çalışmak (iii) Üroloji uzmanlık öğrencisi olan hekimlerde 1 yıldan daha kısa süredir üroloji alanında asistanlık yapmakta olması yer almaktadır. Anketin sadece ilk 4 sorusu açık uçlu sorulardan oluşmakta olup anketin kalanı tamamen kapalı uçlu sorulardan oluşmaktadır. Anket temel olarak 4 bölümden oluşmaktadır. Bu bölümlerde klinik deneyimler, RHS hastalarında genel tedavi tercihleri, HBOT hakkındaki bilgi düzeyleri ve RHS hastalarında HBOT uygulaması hakkındaki görüşler sorgulanmıştır. RHS hastalarında HBOT uygulaması hakkındaki görüşlerin sorgulamasında dört adet 3'lü likert tipi soru tercih edilmiştir.

Bu çalışma için 25.02.2020 tarihinde SBÜ Gülhane Eğitim ve Araştırma Hastanesi Girişimsel Olmayan
Araştırmalar Etik Kurulu’ndan (Karar No:2020/86) onay alınmıştır. Ayrıca 13.02.2020 tarihinde ILRSA derneği ve Türk Üroloji Derneği’nden çalışma için izin alınmıştır. Anketin başında çalışmaya dair açıklama yazısı yazılmış olup, anketin doldurulması onam olarak kabul edilmiştir.

İstatistiksel analizler için SPSS paket program 21 kullanılmıştır. Veriler $\mathrm{n}(\%)$ veya ortalama \pm standart sapma olarak belirtilmiştir. Boş bırakılan cevaplar, o soruya ait istatistiksel analizlere dahil edilmemiştir. Normal dağılım analizinde Kolmogrov-Smirnov testi kullanılmıştır. Grupların karşılaştırılmasında Ki-Kare veya Fisher kesin test kullanılmıştır. P değeri $<0,05$ istatistiksel olarak anlamlı kabul edilmiştir.

\section{BULGULAR}

Anketimizi toplam 77 üroloji hekimi yanıtladı. Çalışmaya katılanların tamamı erkekti ve en çok katılım $(\%$ 64,9) Ankara'dan idi. Hekimlere ait demografik veriler Tablo 1'de gösterilmiştir.

Tablo 1. Ankete katılan üroloji hekimlerine ait demografik veriler (Veriler ortalama \pm SS veya n(\%) şeklinde verilmiştir) (SS: standart sapma)

\begin{tabular}{llc}
\hline & & Ortalama \pm SS veya n(\%) \\
\hline Yaş & & $37,6 \pm 10,9$ \\
Üroloji alanında deneyim $(y \mathbf{l})$ & $11 \pm 10,5$ \\
\hline Ünvan & & $36(\% 46,8)$ \\
\hline$\bullet$ & Asistan & $12(\% 15,6)$ \\
$\bullet$ & Uzman & $6(\% 7,8)$ \\
$\bullet$ & Doktor Öğretim Üyesi & $11(\% 14,3)$ \\
$\bullet$ & Doçent & $12(\% 15,6)$ \\
$\bullet$ & Profesör & $23(\% 29,9)$ \\
\hline Çalışlan kurum türü & $46(\% 59,7)$ \\
\hline$\bullet$ & Üniversite & $3(\% 3,9)$ \\
$\bullet$ & Eğitim Araştırma Hastanesi & $4(\% 4)$ \\
$\bullet$ & Devlet Hastanesi & $1(\% 1,3)$ \\
\hline
\end{tabular}




\section{a. Klinik Deneyim}

Hekimlerin 15'i (\%19,5) RHS nedeniyle hiç başvuru almadığını belirtti. Kendilerine sıklıkla ( $\mathrm{n}=65$, $\% 84,4$ ) bir yılda ortalama 0-10 RHS hatasının başvurduğunu bildirdi. Bir yılda 10-30 arası RHS hastasının başvurduğu 7 hekim $(\% 9,1), 30-50$ arası RHS hastası başvuran ise sadece bir hekim $(\% 1,3)$ vardı. RHS tanısı alan hastalar için doktorlarımızın genel tedavi tercihleri Şekil 1' de gösterilmiştir. Diğer tedaviler olarak belirten hekimler açıklamaya HBOT tercih ettiklerini bildirmiştir.

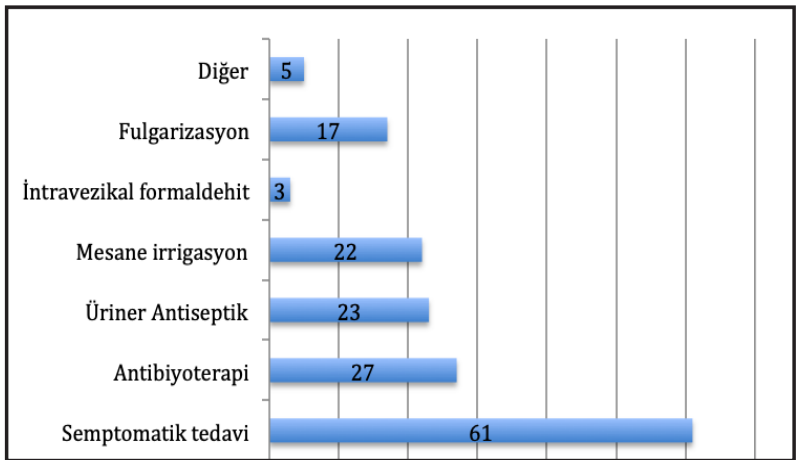

Şekil 1. Radyasyon sistitinde tedavi tercihleri dağılımı

\section{b. HBOT Tercihleri}

Hekimlerimize HBOT yönlendirme sıklıkları sorulduğunda çoğunluk ( $\mathrm{n}=47, \% 61)$ hiçbir zaman yönlendirmediklerini belirtti. Hekimlerin 22'si $(\% 28,6)$ bazen, 4 'ü $(\% 5,2)$ genellikle, 3 'ü $(\% 3,9)$ her zaman hastalarını HBOT için yönlendirdiklerini belirtti. Sorulara yanıt vermeyenler ise hekimlerin \%1,3'ünü oluşturuyordu. HBOT tercih eden hekimler $(\mathrm{n}=30)$ arasinda çoğunluğunun $(n=29, \% 96,7)$ diğer tedavilere yanıtsız olguları HBOT için yönlendirdikleri görüldü. Sadece 1 hekim $(\% 3,3)$ RHS hastalarını ilk tanı aldığında HBOT için yönlendirdiğini belirtti.

Hekimlerimizin çoğunluğu $(n=19, \% 57,6)$ RHS hastalarını HBOT için yönlendirirken tercih ettikleri bir merkez olmadığ 1 cevabını verdi. HBOT raporu çıkartan sadece 8 hekim $(\% 24,2)$ olduğu görüldü.

Hekimlerimize hastalarının HBOT'den fayda görüp görmediklerini nasıl değerlendirdikleri soruldu. Sıklikla klinik bulgular $(\mathrm{n}=44, \% 57,1)$ ve anamnez $(\mathrm{n}=41$,
$\% 53,2)$ tercih edilirken; ardından sirasıyla kan ve idrar tetkikleri $(\mathrm{n}=21, \% 27,3)$ ve sistoskopinin $(\mathrm{n}=17$, $\% 22,1)$ tercih edildiği görüldü. HBOT için yönlendirilen hastaları ne sıklıkta kontrole çağırdıkları sorgulandı. Çoğunluk ( $\mathrm{n}=30, \% 39)$ hiçbir zaman kontrole çağırmadığını belirtti. İkinci sıklıkta $(\mathrm{n}=24, \% 31,2)$ ise hekimlerimiz RHS hastalarını HBOT tamamlandıktan sonra kontrole çağırdıkları görüldü.

Sadece bir kişi $(\% 1,3)$ HBOT ile ilişkili bir insan çalışmasına katıldığını bildirmişti. Anketi cevaplayan hekimlerimizden sadece 10'u (\%13) daha önce bir HBOT merkezinde bulunmuștu. Hekimlerimize bulundukları şehirde bir HBOT merkezi olup olmadığ 1 hakkında sorulan soruya; 54 'ü $(\% 70,1)$ bulundukları șehirde bir HBOT merkezi olduğunu, 8’i $(\% 10,4)$ HBOT merkezi olmadığını ve 14 'ü $(\% 18,2)$ ise bilmediğini belirtti. Ayrıca çalıştıkları hastanede bir HBOT merkezi olup olmadığ sorusuna; hekimlerimizden 13'ü $(\% 16,9)$ bilmediğini, 10'u ise (\%13) HBOT merkezi bulunan bir hastanede çalıştığını belirtmişti.

Çalışmamızdaki üroloji doktorları arasından sadece 22 hekimin $(\% 28,6)$ RHS haricinde herhangi başka bir hastalık nedeniyle HBOT için hasta yönlendirmiş olduğu görüldü. Bu hastalıklar sorgulandı; sıklık sırasina göre Fournier gangreni ( $\mathrm{n}=18, \% 23,4)$, kronik yara iyileşmesi ( $n=9, \% 11,7)$, interstisyel sistit $(n=5, \% 6,5)$, testis torsiyonu $(n=5, \% 6,5)$, akut travmatik periferik iskemi $(n=3, \% 3,9)$, tutması şüpheli flep/greft $(n=2$, $\% 2,6)$ ve diğer $(\mathrm{n}=2, \% 2,6)$ olarak belirtilmiști.

\section{c. HBOT Hakkında Genel Bilgi Düzeyi}

Anketin başında ve sonunda hekimlerimizin HBOT hakkındaki bilgi düzeylerini kendilerinin değerlendirmesi istendi. Şekil 2'de detaylı sonuçlar verilmiştir.

HBOT hakkında genel bilgiler sorgulandı. Çalışmaya katılan hekimlerin çoğunluğu $(n=32, \% 41,6)$ ülkemizde sadece birkaç ilde HBOT merkezinin bulunduğunu düşünmekteydi. HBOT tanımı için "yüksek basınç altında kapalı bir ortamda \%100 oksijen solutulan bir tedavi yöntemi” ifadesinin doğru olduğunu belirten hekim sayısı $26(\% 33,8)$ iken; bu tanımın doğru olmadığını belirten $13(\% 16,9)$ hekim olduğu görüldü. 


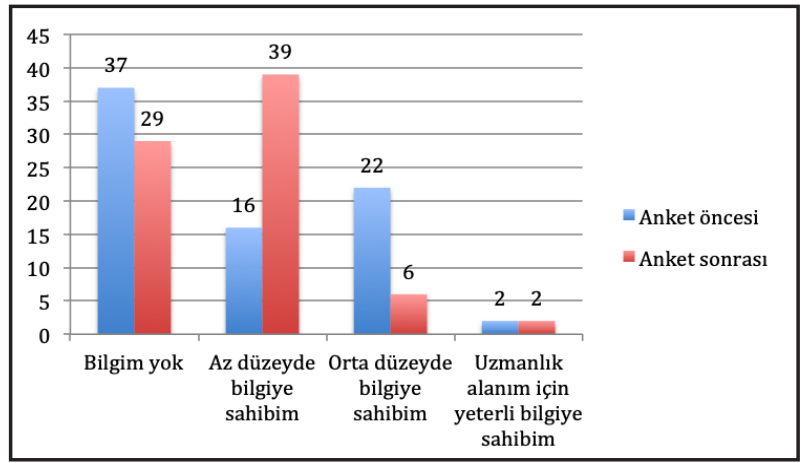

Şekil 2. HBOT hakkındaki bilgi düzeylerinin anket öncesi ve sonundaki karşılaştırması (HBOT: hiperbarik oksijen tedavisi)

Sadece 3 hekim $(\% 3,9)$ çok kişilik basınç odasında radyasyon sistiti için uygulanan tedavi basıncını 2.0 2.5 ATA olarak doğru şekilde belirtirken, benzer şekilde sadece 3 hekim $(\% 3,9)$ çok kişilik basınç odasında radyasyon sistiti için uygulanan tedavi süresini doğru şekilde 120 dakika olarak belirtti. HBOT seansı boyunca oksijenin hastaya hangi yolla verilebileceği sorusuna; 8 hekim $(\% 10,4)$ topikal, 10 hekim $(\% 13)$ özel başlık, 9 hekim $(\% 11,7)$ maske, 2 hekim $(\% 2,6)$ entübe hastalarda entübasyon tüpü yoluyla, 21 hekim $(\% 27,1)$ ise ortamı oksijenlendirerek seçeneğini işaretlemişti. Ankete katılan hekimlerin 43'ü $(\% 55,8)$ ise bu sorunun cevabını bilmediklerini bildirdiler. RHS için ilk sevkte 30 seans HBOT uygulandığını ifade eden sadece 2 $(\% 2,6)$ hekim olduğu görüldü. Sadece 3 hekim $(\% 3,9)$ RHS'de HBOT uygulama siklığının günde 1 seans olarak işaretledi.

RHS'de HBOT'nin genel etki mekanizmaları hakkındaki bilgileri sorgulandi. HBOT'nin genel etki mekanizmalarından bazıları (hiperoksijenasyon, fibro-atrofik dokularda düzelme, anjiyogenez stimülasyonu, anti-inflamatuvar etki, anti-enfektif etki, kollajen formasyonu ve granülasyon dokusunu arttırıcı etki, anti-ödem etki, gaz kabarcıklarının boyutunda küçülme etkisi) sıraland 1 ve hangi mekanizmaların RHS'de faydası olduğunu düşündükleri soruldu. HBOT’nin RHS'de faydası olması beklenen hiperoksijenasyon $(\mathrm{n}=48, \% 62,3)$, fibroatrofik dokularda iyileştirici etkisi $(n=36, \% 46,8)$, anjiyogenez stimulasyonu sağlamas1 $(n=42, \% 54,5)$ ve anti-inflamatuvar etkisi $(n=40$, \%51,9) çoğunluk tarafından doğru cevaplandı.
HBOT’nin komplikasyonları hakkında sorular yöneltildi. HBOT komplikasyonları arasinda bulunan kulak zarında yırtılma ( $\mathrm{n}=22, \% 28,6)$, epilepsi $(\mathrm{n}=9$, $\% 11,7)$, pnömotoraks $(\mathrm{n}=24, \% 31,2)$, kalp yetmezliğinde kötüleşme ( $\mathrm{n}=16, \% 20,8)$ ve kalp pilinin çalışmasında olumsuz etkisi $(\mathrm{n}=11, \% 14,3)$ olabileceğine dair bilgisi olan hekim sayısının az olduğu görüldü. Baş ağrısının $(n=6, \% 7,8)$, böbrek yetmezliğinin ( $n=15$, $\% 19,5)$ ve serebrovasküler olayın $(n=9, \% 11,7)$ HBOT komplikasyonları arasında olmadığını bilen hekim sayısı da benzer şekilde oldukça az idi.

Hekimlerin çoğunluğunun kapalı alan korkusu olan hastaların ( $\mathrm{n}=31, \% 40,3)$ ve psikiyatrik hastalığ olan hastaların $(n=19, \% 24,7)$ HBOT uygulaması için göreceli bir kontraendikasyon taşıdığını bilmekte olduğu görülmüştür. Ayrıca hekimlerin çoğunluğu $(n=32$, $\% 41,6)$ HBOT esnasında güvenlik kurallarına uyulmadığı taktirde yangın gelişebileceğini doğru bilmiştir.

\section{d. HBOT Hakkında Görüşler}

Çalışmamıza katılan hekimlerin çoğunluğu $(n=31$, \%40,3) HBOT'nin radyasyon sistitinde faydası konusunda kararsız olduklarını bildirmişti. HBOT’nin faydalı olduğunu düşünen sadece 18 hekim $(\% 23,4)$ vardı. HBOT’nin etkinliği hakkında hekimlerimizin görüşlerini öğrenebilmek adına daha detaylı sorular yöneltildi. Şekil 3’te soruların cevapları incelenmiştir.

Aktif kanseri olan hastalarda HBOT uygulamaları hakkında üroloji hekimlerinin görüşleri sorgulanmıştır. Hekimlerimizin çoğunluğu aktif kanseri olan hastalarda ( $\mathrm{n}=41, \% 53,2)$ ve kemoterapötik ilaç kullanan hastalarda $(\mathrm{n}=45, \% 58,4)$ HBOT uygulaması hakkında bir bilgilerinin olmadığını bildirmiştir.

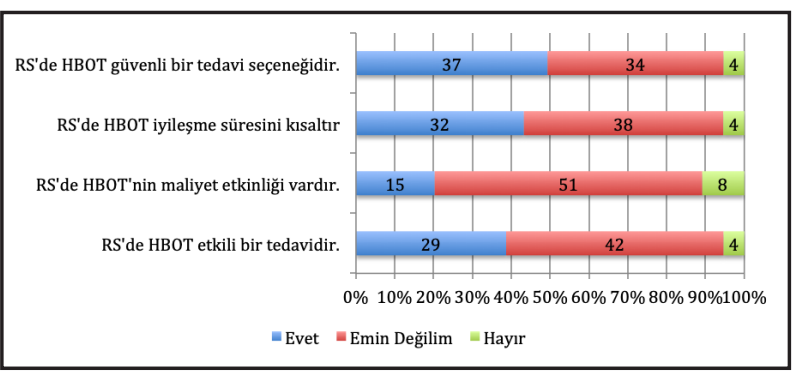

Şekil 3. Üroloji hekimlerinin RHS hastalarında HBOT uygulaması hakkındaki görüşleri (RHS: radyasyona bağlı hemorajik sistit, HBOT: hiperbarik oksijen tedavisi) 


\section{e. Alt Grup Karşılaştırmaları}

Uzmanlık eğitimi almakta olan hekimlerimiz ile uzman olan hekimlerimiz arasında ise HBOT hakkındaki bilgi düzeylerinin, RHS hastalarında HBOT hakkındaki görüşlerinin (etkili olması, maliyet etkinliği, güvenli olması, iyileşmeyi kısaltması) ve RHS dışında HBOT için hasta yönlendirme oranlarının farklı olmadığ 1 görüldü (sırasiyla $\mathrm{p}=0,418, \mathrm{p}=0,162, \mathrm{p}=0,074$, $\mathrm{p}=0,505, \mathrm{p}=0,083)$. Ancak uzmanlık eğitimi almakta olan hekimlerimizin diğer hekimlerimize göre RHS hastalarında HBOT’nin faydalı olduğuna dair görüşlerinin istatistiksel olarak anlamlı farklılık gösterdiği görüldü ( $\mathrm{p}=0,024)$ (Şekil 4).

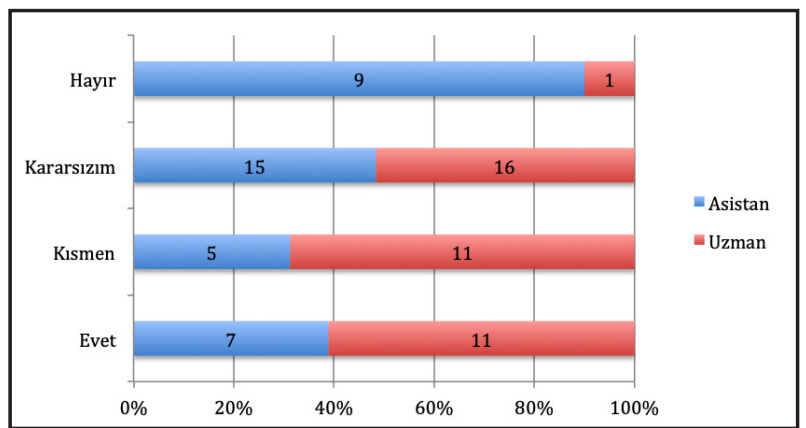

Şekil 4. Ünvanlara göre HBOT'nin RHS'de faydalı olup olmadığına dair görüşlerin dağılımı RHS: radyasyona bağlı hemorajik sistit, HBOT: hiperbarik oksijen tedavisi)

Ayrıca akademik eğitim verilen kurumların yanıtlarındaki farkı saptamak adına üniversitede çalışan hekimlerin yanıtları diğer kurumlar ile karşılaştırıldı. RHS hastalarını rutin olarak HBOT'ye yönlendirme hakkındaki düşüncelerinin, HBOT hakkındaki bilgi düzeylerinin, HBOT’nin RHS hastalarında etkili bir tedavi olup olmadığına dair düşüncelerinin ve RHS d1şında başka bir hastalık için HBOT'ye hasta yönlendirme oranlarının arasında anlamlı bir fark olmadığı görüldü. (sırasiyla $\mathrm{p}=0,420, \mathrm{p}=0,265, \mathrm{p}=0,301, \mathrm{p}=0,851$ )

Hekimlerimize RHS nedeniyle başvuru olan ve olmayanlar arasındaki HBOT bilgi düzeyi, HBOT hakkındaki görüşler ve HBOT’ye başka bir hastalık için hasta yönlendirme oranları karşılaştırıldı (Tablo 2). Ayrıca, HBOT hakkında bilgisi olan $(\mathrm{n}=40)$ ve hiç bir bilgisi olmadığını $(n=37)$ beyan eden hekimlerimizin RHS hastalarını HBOT’ye yönlendirme oranları, HBOT hakkındaki görüşleri ve RHS dışında başka bir hastalık için HBOT’ye hasta yönlendirme oranları karşılaştırıldı (Tablo 3).

\section{TARTIŞMA}

Çalışmamıza katılan ve üroloji alanında aktif çalışan 77 hekimin 47'sinin (\% 61) RHS hastalarını HBOT için hiçbir zaman yönlendirmedikleri görülmüştür. Benzer şekilde hekimlerin çoğunluğu ( $\mathrm{n}=31, \%$ 40,3) HBOT'nin RHS'de faydası konusunda kararsiz olduğunu bildirmiştir. Ayrıca, 29 hekim (\% 37,7) HBOT hakkında hiçbir fikri olmadığını belirtmiştir. HBOT hakkında hiçbir bilgisi olmayan hekimlerin, diğer hekimlere göre HBOT hakkındaki görüşlerinin ve RHS nedeniyle HBOTye hasta yönlendirme oranlarının istatistiksel olarak anlamlı şekilde daha olumsuz olduğu tespit edildi. Son olarak, RHS başvurusu alan hekimlerin, RHS başvurusu almayan hekimlere göre HBOT hakkındaki görüşlerinin istatistiksel olarak daha olumlu olduğu görüldü. Bu çalışma sonucunda üroloji alanında uzmanlık yapan hekimlerin HBOT hakkında bilgilerinin ve farkındalıklarının arttırılmasına ihtiyaç olduğunu gördük.

HBOT klinik amaçlarla uygulandığında kapalı bir alanda 1.4 ATA (atmosfer absolut) basınç veya üzerindeki basınçlarda aralıklı olarak \% 100 oksijen solutulan bir tedavi yöntemidir. HBOT esnasında hastaya maske ile, entübasyon tüpü yoluyla, özel bir başlık aracıllğı ile veya ortamı \% 100 oksijenle basınçlandırılarak oksijen solutulur. HBOT, tüm dünyada birçok endikasyonda etkin bir şekilde uygulanmaktadır. Amerika'da bulunan Sualtı Hekimliği ve Hiperbarik Tip Derneği (Undersea and Hyperbaric Medicine Society-UHMS) ve Avrupa Hiperbarik Tip Komitesi (European Committee of Hyperbaric Medicine-ECHM) tarafından radyasyon sistiti bir HBOT endikasyonu olarak kabul edilmiştir $(9,13)$. Vasküler obliterasyon ve stromal fibrozis ile karakterize radyasyon hasarı gelişmiş bir dokuda HBOT'nin temel terapötik etki mekanizmaları arasında anjiyogenezi uyarması, dokunun oksijenasyonunu arttırması, fibrozisi azaltması ve bu dokulara kök hücre mobilizasyonunu uyarması yer almaktadır (9). $\mathrm{Bu}$ amaçla RHS hastalarında, HBOT ilk başvuruda 30 seans uygulanmakta, gerekli görüldüğü takdirde 60 seansa kadar uzatılabilmektedir (14). UHMS tarafindan tavsiye edilen tedavi protokolü 2-2.5 ATA basınçta 90120 dakika boyunca \%100 oksijen solutulmasıdır (9). 
Tablo 2. Radyasyon sistiti başvurusu olan ve hiç radyasyon sistiti başvurusu olmayan üroloji hekimleri arasındaki karşılaştırmalar (RHS: radyasyona bağlı hemorajik sistit), HBOT: hiperbarik oksijen tedavisi)

\begin{tabular}{|c|c|c|c|c|c|}
\hline \multicolumn{6}{|c|}{ HBOT hakkında yeterli bilgiye sahip misiniz? } \\
\hline & Evet & Kismen & Çok az & Hayır & P değeri \\
\hline RHS başvurusu olan & 1 & 22 & 14 & 25 & \multirow{2}{*}{$0,012^{*}$} \\
\hline RHS başvurusu olmayan & 1 & 0 & 2 & 12 & \\
\hline \multicolumn{6}{|c|}{ RHS'de HBOT uygulaması etkili bir tedavi seçeneğidir. } \\
\hline & Evet & \multicolumn{2}{|c|}{ Emin değilim } & Hayır & P değeri \\
\hline RHS başvurusu olan & 28 & \multicolumn{2}{|c|}{33} & 0 & \multirow{2}{*}{$<0,001^{*}$} \\
\hline RHS başvurusu olmayan & 1 & & & 4 & \\
\hline \multicolumn{6}{|c|}{ RHS'de HBOT maliyet etkinliği olan bir tedavi seçeneğidir. } \\
\hline & Evet & \multicolumn{2}{|c|}{ Emin değilim } & Hayır & P değeri \\
\hline RHS başvurusu olan & 13 & \multicolumn{2}{|c|}{43} & 4 & \multirow{2}{*}{0,058} \\
\hline RHS başvurusu olmayan & 2 & & & 4 & \\
\hline \multicolumn{6}{|c|}{ RHS’de HBOT uygulaması iyileşme süresini kısaltır. } \\
\hline & Evet & \multicolumn{2}{|c|}{ Emin değilim } & Hayır & P değeri \\
\hline RHS başvurusu olan & 30 & \multicolumn{2}{|c|}{30} & 0 & \multirow{2}{*}{$<0,001^{\star}$} \\
\hline RHS başvurusu olmayan & 2 & & & 4 & \\
\hline \multicolumn{6}{|c|}{ RHS’de HBOT güvenli bir tedavi seçeneğidir. } \\
\hline & Evet & \multicolumn{2}{|c|}{ Emin değilim } & Hayır & P değeri \\
\hline RHS başvurusu olan & 33 & \multicolumn{2}{|c|}{28} & 0 & \multirow{2}{*}{$<0,001^{\star}$} \\
\hline RHS başvurusu olmayan & 4 & & & 4 & \\
\hline \multicolumn{6}{|c|}{ Daha önce RHS dışında başka bir hastalık için HBOT’ne hasta yönlendirdiniz mi? } \\
\hline \multicolumn{4}{|c|}{ Evet } & Hayır & P değeri \\
\hline \multirow{2}{*}{$\begin{array}{l}\text { RHS başvurusu olan } \\
\text { RHS başvurusu olmayan }\end{array}$} & 22 & & & 39 & \multirow{2}{*}{$0,004^{*}$} \\
\hline & 0 & & & 15 & \\
\hline
\end{tabular}

Tablo 3. HBOT hakkında hiçbir bilgisi olmayan hekimler $(n=37)$ ile diğer hekimlerin $(n=40)$ karşılaştırması (HBOT: hiperbarik oksijen tedavisi, RHS: radyasyona bağlı hemorajik sistit)

\begin{tabular}{|c|c|c|c|c|c|}
\hline \multicolumn{6}{|c|}{ RHS hastalarını HBOT'ne yönlendiriyor musunuz? } \\
\hline & Hiçbir zaman & Bazen & Genellikle & Her zaman & $P$ değeri \\
\hline Bilgisi var & 12 & 20 & 4 & 3 & \multirow{2}{*}{$<0,001^{*}$} \\
\hline Hiç bilgisi yok & 35 & 2 & 0 & 0 & \\
\hline \multicolumn{6}{|c|}{ RHS ‘de HBOT uygulaması etkili bir tedavi seçeneğidir. } \\
\hline & Evet & Emin değilim & Hayır & & $\mathrm{P}$ değeri \\
\hline Bilgisi var & 22 & 14 & 2 & & $0,002^{*}$ \\
\hline Hiç bilgisi yok & 7 & 28 & 2 & & \\
\hline \multicolumn{6}{|c|}{ RHS ‘de HBOT maliyet etkinliği olan bir tedavi seçeneğidir. } \\
\hline & Evet & Emin değilim & Hayır & & $\mathrm{P}$ değeri \\
\hline Bilgisi var & 13 & 19 & 5 & & $0,003^{*}$ \\
\hline
\end{tabular}




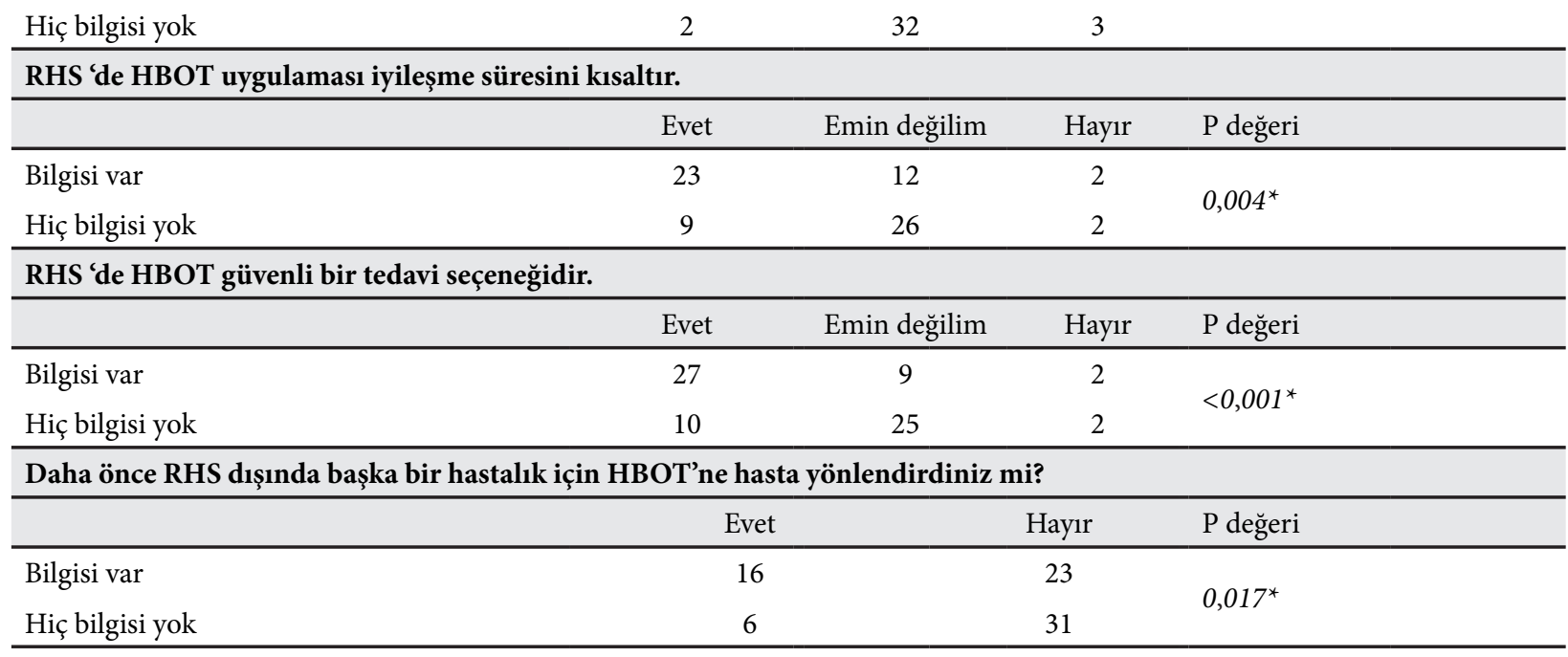

RHS ve HBOT ile ilgili birçok çalışma bulunmaktadır. American Heart Association (AHA) skorlamasinda göre RHS'de HBOT uygulaması kanıt seviyesi $1 \mathrm{~b}$ olarak bildirilmiştir (9). Cardinal ve ark 2018 yılında bir üroloji dergisinde yayınladıkları meta-analizde 426 çalışma arasından değerlendirmeye alınma kriterlerini sadece 16 çalışma (toplam 602 hasta) sağlamıştır. Sadece bir çalışmanın, randomize kontrollü bir çalışma olduğuna dikkat çekilmiştir. RHS nedeniyle "Radiation Therapy Oncology Group/European Organization for Research and Treatment of Cancer" (RTOG/EORTC) evrelemesi kullanmış olan 7 çalışmada hastaların \% 75'inde hematüri evresinde en az 1 evre iyileşme olduğu görülmüştür. Uzun dönem takip (en az 1 yıl) yapılan 499 hastada hematürideki rekürrens oranı \% $14(\mathrm{n}=17)$ olarak saptanmıştır. Yedi çalışmada ise ortalama relaps süresi hesaplanmış olup; ortanca değer 10 ay (6-16,5 ay) olarak bildirilmiştir. Sonuç olarak yazarlar HBOT uygulanan RHS hastalarında cevap oranının \%84 olduğunu belirtmiş ve bu hastalarda HBOT kullanımını desteklemiştir (12). Oscarsson ve ark tarafından randomize kontrollü faz 2-3 çalışması 2019 yılında "Lancet Oncology" dergisinde yayınlanmıştır. $\mathrm{Bu}$ çalışmada 42 hasta HBOT grubuna, 45 hasta ise kontrol grubuna alınmıştır. HBOT protokolünde haftada 5 seans, toplamda 30-40 seans olmak üzere 2.42.5 ATA basınçta 80-90 dakika boyunca \%100 oksijen solutulmuştur. Kontrol grupta ise daha önce önerilen tedaviler değiştirilmemiştir. Çalışmanın sonucunda
HBOT’nin hasta semptomlarında anlamlı iyileşme ve yaşam kalitesinde anlamlı düzelme sağladığı saptanmıştır. Yazarlar RHS tedavisinde HBOT’nin güvenli ve iyi tolere edilen bir tedavi olduğunu vurgulamıştır (15). Bu iki çalışma da Q1 dergi kategorisindeki önemli üroloji ve onkoloji dergilerinde yayınlanmıştır.

RHS'de HBOT uygulaması sonucunda yüksek başarı oranları bildirilen bu çalışmalara rağmen, bizim çalışmamıza katılan hekimlerimizin çoğunluğu $(n=31$, \%40,3) HBOT’nin RHS hastalarındaki faydası konusunda kararsızdı. HBOT’nin faydalı olduğunu düşünen sadece 18 hekim $(\% 23,4)$ vardı. Buna rağmen RHS hastalarını HBOT’ne her zaman veya genellikle yönlendiren hekim sayısı toplam $7(\% 9,1)$ iken çoğunluğun ( $\mathrm{n}=47, \% 61)$ hiçbir zaman HBOT’ye RHS hastası yönlendirmediğini gördük. Ne yazık ki bizim çalışmamizda hekimlerimizin sadece 2'si $(\% 2,6)$ HBOT hakkında kendi uzmanlık alanı için yeterli bilgiye sahip olduğunu düşündüğünü belirtmişti. Ayrıca daha önce HBOT ile ilgili bir çalışmaya katılan sadece 1 hekim $(\% 1,3)$ vard1. Anketi cevaplayan hekimlerin sadece 10 tanesi (\%13) HBOT merkezi bulunan bir hastanede çalıştığını belirtirken; 14 hekim ise $(\% 18,2)$ bulundukları şehirde bir HBOT merkezi olup olmadığını bilmediğini belirtmiştir. Çalışmamıza katılan üroloji doktorlarının HBOT hakkında az düzeyde bilgi sahibi olması ve RHS'de HBOT uygulamasinin faydası hakkında kararsız olmalarının temel sebebi bu konudaki çalışmaların ve HBOT hakkında dökümanların yeterli 
sayıda olmadığını düşündürmüştür. Ne yazık ki, ulusal veritabanı olarak Dergipark'ta "radiation cystitis AND hyperbaric oxygen” olarak tarama yapıldığında sadece 4 çalışmaya ulaşılmakta ve bu çalışmalarda da birincil olarak HBOT'den bahsedilmemektedir (16).

Üroloji dergilerindeki derlemelerde RHS tedavisinde HBOT bir tedavi seçeneği olarak belirtilirken, Üroloji derneklerinin kılavuzlarına bakıldığında, sadece "Canadian Urological Association" (CUA) tarafından 2019 yilında yayınlanan raporda RHS'de HBOT uygulaması hakkında bilgilendirme olduğu görülmüştür $(8,17,18)$. Bu raporda, persistan veya rekürren, klinik olarak anlamlı hematürisi olan stabil RHS hastalarında HBOT önerilmiştir. Özellikle başarısız sistoskopi ve fulgarizasyon olan RHS hastalarında bir erken tedavi seçeneği olarak düşünülmesi gerektiği vurgulanmıştır. HBOT’nin güvenli ve etkili bir tedavi olduğu belirtilmiştir (18). "European Association of Urology" (EAU) kılavuzlarında ise radyasyon sistiti ile ilgili bir bölüm yoktur (19). Son 3 yılda yapılmış önemli uluslararası ve ulusal kongre bildirilerinde de benzer şekilde RHS ve HBOT hakkında sunulan bildirilerin çok az sayıda olduğu görülmüştür. EAU tarafından düzenlenen son 3 kongrede RHS'de HBOT kullanımı ile ilgili sadece 1 bildiri sunulmuştur (20-22). "American Urological Association” (AUA) tarafından düzenlenen son 3 kongrede ise bu konuda bir bildiri sunulmamış olup sadece 3 çalışmada sonuçlarda HBOT ile ilgili hasta verileri bildirilmiştir (23-25). Son 3 yıla ait Ulusal Üroloji Kongre'lerinde ise bu konuda hiçbir bildiri sunulmamıştır (26-28). Ülkemizdeki hekimlerimizin çoğunluğunun HBOT uygulaması hakkındaki bilgi düzeylerinin yetersiz olmasinin ve RHS nedeniyle HBOT'ye hasta yönlendirmemelerinin temel sebebi, HBOT hakkındaki çalışmaların büyük Üroloji organizasyonlarında sunulmaması ve büyük Üroloji dernekleri tarafından yayınlanan kılavuzlarda RHS tedavisinin yer almaması olabilir.

Ne yazık ki, ülkemizde ve dünyada HBOT merkezleri her şehirde bulunmamaktadır; bu nedenle bu tedaviye erişim kısıtlıdır $(11,29)$. Ülkemizde sadece 21 ilde en az bir HBOT merkezi bulunmaktadır (11). Bu sebeple, tıp fakültesi öğrencileri ve uzmanlık öğrencileri de eğitimleri boyunca bir HBOT merkezinde bulunma ve HBOT hakkında bilgi edinme firsatını genellikle yakalayamamaktadır. Ayrıca çalışmamızda hekimlerimizin HBOT merkezleri hakkındaki farkındalıklarının da az olduğunu göze çarpmıştır. Çalışmamıza aktif bir HBOT merkezi olmayan bir ilden (Afyon, Isparta, Samsun) katılan sadece 3 hekim vardı. Buna rağmen çalıştıkları ilde HBOT merkezi olmadığını belirten 8 hekim $(\% 10,4)$ ve bu konuda bir fikri olmayan ise 14 hekim $(\% 18,2)$ vardı. Diğer yandan, çalıştıkları hastanede HBOT merkezi olup olmadığını bilmeyen 13 hekim $(\% 16,9)$ olduğu görüldü. HBOT merkezleri hakkındaki farkındalığın az olması tıp fakültesi eğitiminde HBOT hakkında bilgi edinilememesi ile açılanabilir.

Diğer yandan akademik eğitimin olduğu kurumların yaklaşımını ayrı olarak değerlendirdik. Benzer şekilde üniversitede çalışan hekimlerimizin diğer kurumlardaki hekimlere göre HBOT hakkındaki bilgi düzeylerinin veya RHS hastalarında HBOT'nin etkili bir tedavi olması hakkındaki görüşlerinin değişmediği görüldü (sırasıyla $\mathrm{p}=0,420, \mathrm{p}=0,265$ ). Bu durum HBOT merkezlerinin Türkiye genelinde çok yaygın olmaması, Üroloji derneklerine ait kılavuzlarda verilen bilgilerin yetersiz olması, ulusal bilimsel veritabanlarımızda bu konuda makale olmaması, uluslararası ve ulusal Üroloji kongrelerinde yetersiz sayıda bildiri olması, Üroloji hekimlerinin HBOT hakkındaki ilgilerinin az olmasını açıklayabilir. Ancak hekimlerimizin HBOT hakkında az da olsa bilgi sahibi olmalarının, RHS hastalarını HBOT'ye yönlendirme oranlarında ve HBOT hakkındaki görüşlerinde anlamlı şekilde olumlu değişiklikler yaptığı görülmüştür. (Tablo 3) Burada hekimlerimizin teorik bilgilerini arttırmanın önemini tekrar vurgulamak istiyoruz.

Çalışmamızda RHS başvurusu olan hekimlerimizin, RHS başvurusu hiç olmayanlara göre HBOT hakkındaki bilgi düzeylerinin ve RHS'de HBOT uygulaması hakkındaki görüşlerinin olumlu yönde anlam1 farklılık gösterdiğini gördük (Tablo 2). Bu durum, hekimlerimizin teorik bilgilere, mesleki deneyimlerle beraber ulaşma çabalarının arttığını göstermektedir. Bir diğer önemli nokta ise, teorik bilgilerin yanı sıra hekimlerin deneyimlerinin de görüşlerinin şekillen- 
mesinde çok önemli bir faktör olduğudur. HBOT merkezlerinin kısıtlı sayıda olması nedeniyle uzmanlık eğitimleri boyunca hekimlerimizin RHS olan hastalarında HBOT hakkında deneyimleri fazla değildir. Bu nedenle, hekimlerimiz uzmanlıklarında da RHS hastalarını HBOT için yönlendirmekte çekimser kalmaktadır.

$\mathrm{Bu}$ çalışmaya dahil edilen örneklemin tüm Türkiye genelinden olmaması, uzmanlık öğrencilerinin sayısının nispeten fazla olması çalışmanın temel kısıtlılıklarıdır. Diğer yandan, anketin uzunluğu soruların dikkatli cevaplanmasında bir dezavantaj olmuştur. Son olarak, hekimlerin daha öncesinde çalıştıkları kurumlar ve uzmanlık eğitiminin etkisi bu çalışmada değerlendirilememiştir.

\section{SONUÇ}

Sonuç olarak, bu çalışmada üroloji hekimlerimizin HBOT hakkındaki bilgi düzeylerinin yeterli olmadığını, RHS'de HBOT uygulaması hakkında hekimlerimizde kararsızlığın hakim olduğunu ve pratik uygulamada hekimlerimizin çoğunluğunun RHS hastalarını HBOT için yönlendirmediklerini fark ettik. İkincil amacımız ise RHS'de etkili bir tedavi seçeneği olan HBOT hakkında üroloji hekimlerimizde farkındalık oluşturmaktı. $\mathrm{Bu}$ doğrultuda ankete katılan 77 üroloji hekiminde ve bu çalışmayı okuyan diğer hekimlerimizde de RHS'de HBOT’nin de bir tedavi seçeneği olduğuna dikkat çekebildiğimizi düşünüyoruz. Kendi adımıza, Üroloji alanında RHS hastalarında HBOT pratikleri açısından Üroloji kılavuzları, uluslararası ve ulusal Üroloji kongrelerde ve Türkiye'deki bilimsel dergilerde çok az sayıda bilimsel çalışmanın sunulduğunu gördük. Ülkemizde, HBOT hakkındaki farkındalığı ve bilgi düzeyini arttırmak amacıyla bu platformlarda bilimsel açıdan kaliteli yayınlar ve bildiriler ile Sualtı Hekimliği ve Hiperbarik Tıp uzmanlarının deneyimlerini paylaşmaları gerektiğini fark ettik.

\section{Finansal Destek}

Yazarlar bu çalışma için mali destek almadıklarını beyan etmişlerdir.

\section{Çıkar Çatışması}

Yazarlar çıkar çatışması olmadığını beyan ederler.

\section{Etik Kurul}

$\mathrm{Bu}$ çalışma Sağlık Bilimleri Üniversitesi Gülhane Eğitim Araştırma Hastanesi Etik Kurulu tarafından 25 Şubat 2020 tarihinde 2020-86 karar numarası ile etik açidan uygun bulunmuştur.

\section{Teşekkür}

ILRSA Derneği başkanı Prof. Dr. Yaşar Özgök’e ve Türk Üroloji Derneği İç Anadolu Şubesi başkanı Prof. Dr. Halil Başar’a teşekkür ederiz.

\section{KAYNAKLAR}

1. Lobo N, Kulkarni M, Hughes S, et al. Urologic complications following pelvic radiotherapy. Urology 2018; 122:1-9.

2. Corman JM, McClure D, Pritchett R, Kozlowski P, Hampson NB. Treatment of radiation induced hemorrhagic cystitis with hyperbaric oxygen. J Urol. 2003; 169(6):22002202.

3. Mendenhall WM, Henderson RH, Costa JA, et al. Hemorrhagic radiation cystitis. Am J Clin Oncol. 2015; 38(3): 331-336.

4. Crew JP, Jephcott CR, Reynard JM. Radiation-induced haemorrhagic cystitis. Eur Urol. 2001; 40: 111-123.

5. Levenback C, Eifel PJ, Burke TW, Morris M, Gershenson DM. Hemorrhagic cystitis following radiotherapy for stage Ib cancer of the cervix. Gynecol Oncol. 1994; 55(2): 206210.

6. Nicholas S, Chen L, Choflet A, et al. Pelvic radiation and normal tissue toxicity. Semin Radiat Oncol. 2017; 27(4):358-369.

7. Wein AJ, Kavoussi LR, Partin AW, et al. Campbell-Walsh Urology. 11th ed. Philadelphia: Elsevier, 2016

8. Pascoe C, Duncan, C, Lamb, BW. et al. Current management of radiation cystitis: a review and practical guide to clinical management. BJU Int. 2019; 123(4):585-594.

9. Weaver LK. Hyperbaric oxygen therapy indication. 13th ed. North Palm Beach, FL: Best Publishing Company, 2014.

10. Horan N, Cooper JS. Radiation cystitis and hyperbaric management. [Statpearls review] In: StatPearls, 2020. Treasure Island (FL): StatPearls Publishing.

11. Sualtı ve Hiperbarik Tip Derneği. [Internet anasayfası] Tarih yok. [Alıntı tarihi: 27 Ekim 2020]. Erişim linki: http:// sualti.org/?page_id=11 doi: 10.1007/s11934-018-0790-3 
12. Cardinal J, Slade A, McFarland M, et al. Scoping review and meta-analysis of hyperbaric oxygen therapy for radiation-induced hemorrhagic cystitis. Curr Urol Rep. 2018; 19(6):38.

13. Mathieu D, Marroni A, Kot J. Tenth European Consensus Conference on Hyperbaric Medicine: recommendations for accepted and non-accepted clinical indications and practice of hyperbaric oxygen treatment. Diving Hyperb Med. 2017; 47(1):24-32.

14. Resmi Gazete. Sağllk Uygulama Tebliği [Internet] 2013. [Güncelleme 09.05.2020; Alıntı tarihi 02.12.2020]. Erişim linki: https://www.resmigazete.gov.tr/eskiler/2020/05/20200509-21.pdf

15. Oscarsson N, Müller B, Rosen A, et al. Radiation-induced cystitis treated with hyperbaric oxygen therapy(RICH-ART): a randomised, controlled, phase 2-3 trial. Lancet Oncol. 2019; 20:1602-1614.

16. DergiPark Akademik "radiation cystitis AND hyperbaric oxygen” Arama Sonuçları. [Internet] 2020. [Alıntı tarihi 27.10.2020]. Erişim linki: https://dergipark.org.tr/tr/search?q=radiation+cystitis+AND+hyperbaric+oxygen\&section $=$ articles

17. Thompson A, Adamson A, Bahl A, et al. Guidelines for the diagnosis, prevention and management of chemical- and radiation-induced cystitis. J Clin Urol. 2014; 7:25-35.

18. Goucher G, Saad F, Lukka H, et al. Canadian Urological Association Best Practice Report: Diagnosis and management of radiation-induced hemorrhagic cystitis. Can Urol Assoc J. 2019; 13:15-23.

19. European Association of Urology Guidelines. [Internet anasayfası] Tarih yok. [Alıntı tarihi: 27 Ekim 2020]. Erişim linki: https://uroweb.org/guidelines/

20. EAU20.[Internet] Tarih yok. [Alıntı tarihi: 27 Ekim 2020]. Erişim linki: https://resource-centre.uroweb.org/resource-centre/eau20

21. EAU19. [Internet] Tarih yok. [Alıntı tarihi: 27 Ekim 2020]. Erişim linki: https://urosource.uroweb.org/resource-centre/eau19
22. EAU18. [Internet anasayfasi] Tarih yok. [Alıntı tarihi: 27 Ekim 2020]. Erişim linki: https://urosource.uroweb.org/ resource-centre/eau 18

23. AUA Journals, AUA Annual Meeting Program Abstracts 2019, "hyperbaric" Search Results. [Internet anasayfası] Tarih yok. [Alıntı tarihi: 27 Ekim 2020]. Erişim linki: https://www.auajournals.org/action/doSearch?AllField=hyperbaric\&ContentGroupKey=10.1016\%2Fjuro.2019.201. issue-Supplement_4

24. AUA Journals, AUA Annual Meeting Program Abstracts 2018, "hyperbaric" Search Results. [Internet anasayfası] Tarih yok. [Alıntı tarihi: 27 Ekim 2020]. Erişim linki: https:// www.auajournals.org/action/doSearch?AllField=hyperbaric\&ContentGroupKey=10.1016\%2FS0022534718X00020

25. Science Direct, "hyperbaric" Search Results in 2017 AUA conference abstracts. [Internet anasayfası] Tarih yok. [Alıntı tarihi: 27 Ekim 2020]. Erişim linki: https://www. sciencedirect.com/search?qs=hyperbaric\&pub $=$ The $\% 20$ Journal\%20 of\%20Urology\&cid=273470\&articleTypes $=$ ABS\&years $=$

26. Türk Üroloji Derneği, 28. Ulusal Üroloji Kongresi (2019) [Internet anasayfası] Tarih yok. [alıntı tarihi: 27 Ekim 2020]. Erişim linki: https://www.uro365.org/category/ kongreler/28-ulusal-uroloji-kongresi-2019/

27. Türk Üroloji Derneği, 27. Ulusal Üroloji Kongresi (2018) [Internet anasayfası] Tarih yok. [Alıntı tarihi: 27 Ekim 2020]. Erişim linki: https://www.uro365.org/category/ kongreler/27-ulusal-uroloji-kongresi-2018/

28. Türk Üroloji Derneği, 26. Ulusal Üroloji Kongresi (2017) [Internet anasayfasi] Tarih yok. [Alıntı tarihi: 27 Ekim 2020]. Erişim linki: https://www.uro365.org/category/ kongreler/26-ulusal-uroloji-kongresi-2017/

29. Oxynet, HBOT Centers [Internet] Tarih yok. [Alıntı tarihi: 27 Ekim 2020]. Erişim linki: http://www.oxynet.org/03HBOCenters/Index03.php 